\title{
Impact of Reflective Writing and Labatorials on Student Understanding of Force and Motion in Introductory Physics
}

\author{
Calvin S. Kalman ${ }^{1}$, Mark Lattery ${ }^{2}$, Mandana Sobhanzadeh ${ }^{3}$ \\ ${ }^{1}$ Concordia University, Montréal, Canada \\ ${ }^{2}$ University of Wisconsin, Oshkosh, USA \\ ${ }^{3}$ Mount Royal University, Calgary, Canada \\ Email: *Calvin.Kalman@concordia.ca
}

How to cite this paper: Kalman, C. S., Lattery, M., \& Sobhanzadeh, M. (2018). Impact of Reflective Writing and Labatorials on Student Understanding of Force and Motion in Introductory Physics. Creative Education, 9, 575-596.

https://doi.org/10.4236/ce.2018.94041

Received: February 28, 2018

Accepted: April 9, 2018

Published: April 12, 2018

Copyright $\odot 2018$ by authors and Scientific Research Publishing Inc. This work is licensed under the Creative Commons Attribution International License (CC BY 4.0).

http://creativecommons.org/licenses/by/4.0/

\begin{abstract}
In this paper, we examine a way to deal with alternative student conceptions about force and motion in a university level introductory physics course. The course combines Reflective Writing, an activity that engages students in textual material metacognitively, and Labatorials, an in-class active learning intervention. Semi-structured interviews and student writing provide evidence of conceptual change.
\end{abstract}

\section{Keywords}

Inquiry, Reflective Writing, Critical Thinking, Incommensurability, Conceptual Change

\section{Introduction}

A general consensus exists among physics education researchers that changing students' views about force and motion is exceedingly difficult (Chi, 2013; McDermott \& Redish, 1999, and references therein). The nature and scope of the problem is described by Vosniadou (2008) and has led to a number of relatively sophisticated interventions (e.g., Kalman \& Rohar, 2010; Lattery, 2017).

Students enter the physics classroom with an intuitive understanding of force and motion based on everyday experiences that can interfere with formal instruction. From infancy, students have experimented with solid bodies. Consider a child pushing a toy truck across a carpet. The child must apply constant pressure to sustain the toy truck with uniform speed. In the child's mind, only this force is required to explain the motion of the truck. Force is therefore closely 
linked with velocity. If the force suddenly ceases, the truck immediately slows down to rest, as if force is transferred into the truck but fades over time.

These common-sense ideas of force and motion directly contradict the Newtonian force concept, so it is not surprising that this concept is difficult for students to learn. In the Newtonian model, force changes the state of motion (velocity) and is a cause of motion, not an entity in the body. Chi (2013) wrote that:

"Although students can readily learn by adding new beliefs [acquired through formal instruction] such as... the definition of acceleration... these newly added beliefs cannot correct a student's conflicting belief that a thrown object acquires or contains some internal force. Moreover, such conflicting beliefs cannot be easily denied or refuted by contradiction [authority]. For example, stating that "a thrown object does not acquire or contain internal forces," or stating that "a thrown object contains some other kind of forces" will not succeed in helping students achieve correct understanding." (p. 51).

Thus, in the context of the physics classroom, the instructor is confronted with the difficult task of bridging student's alterative conceptions with target conceptions (the Newtonian view), two competing ways of thinking that are profoundly different ("incommensurable"). This particular framing of the teaching/learning problem relies on the controversial assumption that physics-naïve students either possess alternative "theories" for force and motion, or, with minimal intervention, can readily develop them (Kalman \& Rohar, 2010; Lattery, 2017).

In this study, Reflective Writing was used in combination with a new style of introductory physics labs called "Labatorials" at Mount Royal University (MRU). The impact of these pedagogical tools on student learning, and in particular on how students learn the concepts of force and motion, is investigated and analyzed. Interviews at the beginning and end of the semester as well as an analysis of students' Reflective Writing assignments helped us find out how students' understanding of force and motion change during the semester. The basic research question is: do students appear to significantly increase their knowledge of Newton's theory of force when exposed to the above interventions?

\section{Incommensurability and Conceptual Change}

In 1962, Thomas Kuhn (1970) and Paul Feyerabend (1962) both independently introduced the idea of incommensurability to the philosophy of science. In The Structure of Scientific Revolutions, Thomas Kuhn (1970) used the term "incommensurable" to characterize the holistic nature of changes that take place in a scientific revolution. Oberheim \& Hoyningen-Huene (2009) puts it that:

"Problems whose solution was vitally important to the older tradition may temporarily disappear, become obsolete or even unscientific. On the other hand, problems that had not even existed, or whose solution had been considered trivial, may gain extraordinary significance in the new tradition. Kuhn concluded that proponents of incommensurable theories have different conceptions of their 
discipline and different views about what counts as good science; and that these differences arise because of changes in the list of problems that a theory must resolve and a corresponding change in the standards for the admissibility of proposed solutions."

For example, Newton's theory was initially widely rejected because it did not adequately explain the attractive forces between particles of matter, something required of any theory of mechanics from the perspective of the proponents of Aristotle and Descartes' theories (Kuhn, 1970: p. 148). According to Kuhn, with the acceptance of Newton's theory, this question was banished from science as illegitimate, only to re-emerge with the solution offered by general relativity. $\mathrm{He}$ concluded that scientific revolutions alter the very definition of science itself.

Kuhn believed that a mature science experiences alternating phases of normal science and revolutions. He emphasized the difference between normal science that does not change the key theories, instruments, values and existing concepts; (e.g., the discovery of Boyle's law left the concepts of gas, pressure and volume and the instruments used to measure them unchanged) from revolutionary discoveries in which revise the disciplinary matrix to permit the solution of the more serious anomalous puzzles that disturbed the preceding period of normal science (e.g., the discovery of Newton's theory) (Kuhn, 1987/2000). Such developments require replacing existing concepts with new concepts that are incompatible with the older ideas.

Paul Feyerabend (1962) initially introduced the term "incommensurable" and illustrated the incommensurability of scientific theories with a comparison of six pairs of central concepts drawn from three episodes of fundamental theory change in the course of scientific advance. One of these is the dynamical characterization of impetus in the impetus theory of motion and the concept of momentum in the conceptual apparatus of Newtonian mechanics (Oberheim \& Hoyningen-Huene, 2009). Chi (2013) notes that:

"[ T] here are numerous false beliefs about concepts such as force-and-motion or heat-and-temperature across a variety of domains for which conceptual change is very hard to achieve. The robustness of such misconceptions has been demonstrated in literally thousands of studies, about all kinds of science concepts and phenomena, beginning with a book by Novak (1977) and a review by Driver and Easley (1978) both published over three decades ago. By 2008, there were over 8,000 publications describing students' incorrect ideas and instructional attempts to change them (Confrey, 1990; Driver, Rushworth, Squires, \& Wood-Robinson, 1994; Duit, 2009; Ram, Nersessian, \& Keil, 1997), indicating that conceptual understanding in the presence of misconceptions remains a challenging problem." (p. 56).

And later:

"In short, there are many concepts like force and motion, for which one's initial flawed mental model is not transformed to the correct model despite repeated corrections or patchings of the underlying rules... the revised rules did 
not transform the flawed mental model into the correct model, because the implicit underlying core hypotheses were still incorrect from a dimension perspective." (p. 63).

\section{Pedagogical Approaches}

The following subsections table provides a brief introduction to each of the pedagogical approaches used in this research.

\subsection{Pedagogical Tool: Reflective Writing (RW)}

Reflective Writing (Kalman, 2011) is a metacognitive activity, which has students examine textual material, before coming to the classroom in the manner of a hermeneutic circle (Gadamer, 1975/1960). The hermeneutic approach starts by having students initiate a self-dialogue about each textual extract. Within the framework of such a dialogue, there exist two "horizons." There is the horizon that contains everything that a student believes from the particular vantage point of encountering the textual extract. The second horizon encompasses the potential in the textual extract; the sense in which the words, in the textual extract, are related with in the language game understood by the author of the textbook. The student approaches the textual extract with preconceptions (misconceptions) about the material within the textual extract. The key quintessential experience occurs when the student is pulled up short by the textual extract. "Either it does not yield any meaning or its meaning is not compatible with what we had expected" (Gadamer, 1975/1960: p. 237). At this point the dialogue begins. The student questions what is known within the entire horizon (Kalman, 2011: p. 163).

\subsection{Pedagogical Tool: Labatorials (Lbt)}

Labatorials were developed by the Physics Education Development group at the University of Calgary (Sobhanzadeh et al., 2017) inspired by the introductory physics tutorial system in the University of Washington (McDermott \& Shaffer, 1998). The curriculum used at the University of Washington is entitled "Tutorials in Introductory Physics" and was written by the Physics Education Group at the University of Washington. The Tutorials are worksheets that require students to work through concepts that have been identified by research to be particularly difficult. Some require students to perform experiments. However, there is still a traditional laboratory system for the first year physics courses at the University of Washington.

"Labatorial" comes from a combination of "laboratory" and "tutorial". In this new style of lab, students use a worksheet with conceptual questions, calculation problems, and instructions for experiments and computer simulations. Labatorials highlight physics concepts covered in lectures and encourage students to present and share their ideas with one another. Each Lbt worksheet starts with conceptual questions and then asks students to make predictions. After doing 
the experimental part, students need to explain whether their results support their prediction or not. Each lab section has one lab instructor assigned to a maximum of 16 students. In Lbt, students complete an Lbt worksheet in groups of 3 or 4 students. There are usually 3 to 6 checkpoints on each worksheet. The purpose of the checkpoints is to encourage an ongoing interaction between the students and lab instructor. Each time the students reach a checkpoint, they review the answers with the lab instructor. If the answer to a question is wrong or students are not proceeding in the right direction, the lab instructor leads the students to find the correct answer by themselves, exploring and discussing alternative ideas.

\section{Measurement Tools}

The purpose of this study is to investigate whether the combined use of RW and Lbt in an introductory physics classroom leads to conceptual change; i.e., a conversion of pre-existing concepts of force and motion to the Newtonian viewpoint. To measure progress toward this objective, we employed Semi Structured Interviews (SSI) at the beginning and the end of the semester and examined Student Writing Products (SWP) each week during the course. The SSI provides the primary data for this study. Conclusions are based on a triangulation of the data. Detailed descriptions of SSI and SWP are given below.

\subsection{Semi Structured Interviews (SSI)}

We conducted semi-structured interviews with 7 students in fall and winter semesters at the beginning and end of the 13-week course. The interview questions relevant to this paper are found in Appendix A. All interviewees had passed physics in high school (grade 12) and were enrolled in a General Science major. Prior to this study we conducted a pilot study and interviewed three first year students enrolled in Phys1201 course. The pilot study helped assess the feasibility of the project in terms of sampling and analysis. Interview questions were tested in this pilot phase and modified to improve this study. The results of the pilot study are not included in this paper.

The interviews served several purposes. They helped us gather information on how the concepts of force and motion are viewed by a sample of the students. Most importantly, they also allowed us to see if the interpretations we made of the writing products were consistent with what interviewees told us. The Reflective Writing products of 41 other students who did not participate in the interviews were also assessed to improve our understanding of the results. In qualitative studies, interviewing is a major source data needed for understanding the phenomenon under study. We are aware of the fact that interviewing, like any other data collection techniques, has its strengths and its limitations. The interview is one of the best way to find out "what is in and on someone else's mind" (Patton 1982). Interviews allow a lot of detail to be collected that would not normally be easily obtained by other research designs. 


\subsection{Student Writing Products (SWP)}

The second source of qualitative data used in this work was a rubric-based analysis of the students' Reflective Writing products (Appendix B). The rubrics were used both as an independent measure and as a cross-comparator to confirm the accuracy of student self-assessment as expressed in their interviews. We used the rubrics developed by Kalman et al. $(2014,2017)$ to analyze the Reflective Writing assignments. The rubrics had undergone an extensive testing and development to ensure their reliability. Weekly RW products are a good method of examining the regular progress of students to examine if the students use this metacognitive technique to see the difference between their ideas and those found in the textbook and presented in class. SWP analysis was carried out on the work of students who participated in SSI sessions, and on representative samples of students not involved in the interview process. This analysis also served as a good triangulation with the interview data.

\section{Participants}

The study was undertaken at Mount Royal University (MRU). All instructors use clickers in the class. The marking criteria and assignments and activities are the same in all sections. The classroom instructors were not part of our research team. Most students at MRU taking introductory physics courses are enrolled in the General Science majors. All students enrolled as General Science majors have to take Classical Physics I (Phys1201) and Classical Physics II (Phys1202). Students were randomly assigned to all sections by the Registrar's office.

Four first year students enrolled in Phys 1201 course participated in the interviews held in a winter semester. The first interviewee was a student who intended to study geosciences in MRU subsequently referred to as Ahmed. We refer to the second and third students, who planned to study chemistry as Bill and Catherine respectively. The fourth student wished to enter the biology major beginning in his second year and we call him Dan. In the following fall semester, we interviewed three students enrolled in the Phys1201 course. These students all intended to take a general science degree and will be referred to as Elena, Frank, and Gabriella. All interviewees did the same Lbt. They completed 10 Lbt during the semester.

\section{Data Analysis}

\subsection{Student Responses in the Interviews}

We explored what interviewees thought about the "relationship between force and motion" at the beginning of the semester. During the post-interview, we again asked what they had thought about the "relationship between force and motion" at the beginning of the semester and also asked about their present ideas about the relationship between these two concepts. Once it was established that the students' ideas had changed, we asked them to explain the particulars about how the change from the beginning of the semester to their present ideas 
at the end of the semester had occurred. The activities mentioned by students were explored deeply during the interview. Table 1 shows the answers provided in the pre- and post-interviews. All interviewees mentioned Reflective Writing as one of the activities that helped them move from their knowledge about these two concepts at the beginning of the semester to their present ideas.

Ahmed states simply, "Force causes motion" The response is too vague to draw firm conclusions. This could mean that force is required to move thing from rest, or that force is required for any type of motion, including uniform motion. Ahmed's next sentence supports the former. An important milestone in replacing a common-sense "impetus" view of force and motion (Section 1 and 2) with the more-productive Newtonian view is for the student to develop/refine a definition of "motion".

Bill's pre-understanding of the relationship between force and motion was similar to Ahmed. In the post-interview he first explained the relationship between force and accelerations (Newton's second law) and used this relationship to explain accelerated motion and motion with zero acceleration.

Catherine used one sentence to explain the relationship between force and motion in the pre-interview. In the post interview she confirmed her pre-understanding of the relationship between these two concepts before taking this course and provided an example: "if I push a desk and so it moves." This shows that her pre-understanding was formed from her experiences in the life

Table 1. Two pedagogical approaches.

\begin{tabular}{|c|c|}
\hline Reflective Writing (RW) & Labatorials (Lbt) \\
\hline $\begin{array}{l}\text { Metacognitive activity; has students examine } \\
\text { textual material, before coming to the classroom } \\
\text { in the manner of a hermeneutic circle (Gadamer, } \\
\text { 1975/1960). The Hermeneutic approach starts by } \\
\text { having students initiate a self-dialogue about } \\
\text { each textual extract. Within the framework of } \\
\text { such a dialogue, there exist two "horizons": the } \\
\text { horizon that contains everything that a student } \\
\text { believes from the particular vantage point of } \\
\text { encountering the textual extract \& second } \\
\text { horizon encompassing the potential in the } \\
\text { textual extract; sense in which the words, in the } \\
\text { textual extract, are related with in the language } \\
\text { game understood by the author of the textbook. } \\
\text { Student approaches textual extract with } \\
\text { preconceptions (misconceptions). Key } \\
\text { quintessential experience occurs when the } \\
\text { student is pulled up short by the textual extract. } \\
\text { "Either it does not yield any meaning or its } \\
\text { meaning is not compatible with what we had } \\
\text { expected" (Gadamer, 1975/1960: p. 237). At this } \\
\text { point the dialogue begins. The student } \\
\text { questions what is known within the entire } \\
\text { horizon (Kalman, } 2011 \text { : p. } 163 \text { ). }\end{array}$ & $\begin{array}{l}\text { Developed by Physics Education Development } \\
\text { group-University of Calgary (Sobhanzadeh et al., } \\
\text { 2017) inspired by introductory physics tutorial } \\
\text { system at University of Washington (McDermott } \\
\text { \& Shaffer, 1998). "Labatorial" -combination of } \\
\text { "laboratory" and "tutorial": students in groups of } \\
3 \text { or } 4 \text { students use a worksheet with conceptual } \\
\text { questions, calculation problems, and instructions } \\
\text { for experiments and computer simulations. } \\
\text { Worksheet start with conceptual questions and } \\
\text { then asks students to make predictions. After } \\
\text { doing the experimental part, students need to } \\
\text { explain whether their results support their } \\
\text { prediction or notand complete an Lbt worksheet. } \\
\text { Usually } 3 \text { to } 6 \text { checkpoints on each worksheet to } \\
\text { encourage an ongoing interaction between the } \\
\text { students and lab instructor. At a checkpoint, they } \\
\text { review the answers with the lab instructor. If the } \\
\text { answer to a question is wrong or students are not } \\
\text { proceeding in the right direction, the lab } \\
\text { instructor leads the students to find the correct } \\
\text { answer by themselves, exploring and discussing } \\
\text { alternative ideas. }\end{array}$ \\
\hline
\end{tabular}


world. She explained her understanding of the relationship between force and motion at the end of the semester by providing an example and as can be seen in Table 1 it contained more details and differentiated between a uniform motion (no friction) and accelerated motion.

At the beginning of the semester, Dan believed that an agent was needed to create motion. As he explained in the post-interview, he lacked the ability to make a connection between physics concepts before taking this course.

As can be seen in Table 1, Elena's explanation of the relationship between force and motion is based on her observation and life experiences and her understanding is not extended beyond these. She believed that a force was necessary to keep an object moving and provided an example of a car that eventually stops if she doesn't push it. In the post-interview the interviewer asked about her understanding of the relationship between force and motion before taking Phys1201 course and then the interviewer asked her to explain her present ideas about the connection between these two concepts. In the post-interview she explained that a force causes motion but a force is not needed to keep an object in motion.

Even if Frank believed that he didn't use his pre-understanding and it was not easy for him to think about the application of the physics concepts in real life, he used his experience to explain the relationship between force and motion. In the pre-interview he said that he had no idea about the relationship between force and motion and I asked him to guess based on his experiences and observations. In the post-interview, he was confident and provided examples to support his explanation.

In the pre-interview Gabriella explained that force influences the speed of an object. In the post-interview, she talked about the influence of force on both magnitude and direction of velocity. She used Newton's second law to explain the relationship between force and motion in the post-interview.

As you see in Table 2 at the beginning of the semester, all students' ideas about the relationship between force and motion are drawn from real-life experience. They all provided a causal explanation to discuss the relationship between force and motion. Moreover, at the end of the semester, interviewees were able to make comparisons between uniform motion and accelerated motion. For example, at the beginning of the semester Elena believed that "when the applied force is gone the object stops finally". However, at the end of the semester Elena explained that "in a uniform motion the net force is zero".

Toward the end of the semester, interviewees explored the relationship between force and motion for special kinds of motion (uniform motion and accelerated motion) rather than for the general case. Interviewees formed explanations of the relationship between force and motion prior to scientific reflection. Student learning was not a correction by science of prior mistaken ideas, but extension of ideas to idealized situations. An example of an idealized situation is motion of an object without friction such that the object keeps moving with constant velocity while the net force acting on the object is zero. This example 
Table 2. Students' understanding of the relationship between force and motion.

\begin{tabular}{|c|c|c|}
\hline & $\begin{array}{c}\text { Pre-interview } \\
\text { (beginning of the semester) }\end{array}$ & $\begin{array}{c}\text { Post-interview } \\
\text { (end of the semester) }\end{array}$ \\
\hline $\begin{array}{l}\text { Interviewer } \\
\text { prompt }\end{array}$ & $\begin{array}{l}\text { Please share with me your } \\
\text { understanding of the relationship } \\
\text { between force and motion. }\end{array}$ & $\begin{array}{l}\text { Please share with me your understanding of the } \\
\text { relationship between force and motion after } \\
\text { taking the course }\end{array}$ \\
\hline Ahmed & $\begin{array}{l}\text { Force causes motion ... I need to } \\
\text { exert a force on a car to be able to } \\
\text { push it when it is stuck. }\end{array}$ & $\begin{array}{l}\text { Before I didn't know about uniform motion and } \\
\text { accelerated motion. Now I can make a good } \\
\text { connection between uniform motion and } \\
\text { Newton's first law. I can also see the connection } \\
\text { between Newton's second law and an accelerated } \\
\text { motion. Before, I didn't consider various forces } \\
\text { acting on the object but now I first try to draw a } \\
\text { free body diagram and consider all the forces } \\
\text { acting on the object. When we learned about } \\
\text { Newton's laws I learned the accelerated motion } \\
\text { and uniform motion better. For example, it made } \\
\text { more sense to have a zero net force in uniform } \\
\text { motion. }\end{array}$ \\
\hline Bill & $\begin{array}{l}\text { The applied force makes an object } \\
\text { move. }\end{array}$ & $\begin{array}{l}\text { We need a force to change the motion. When } \\
\text { there is a force then there is an acceleration and } \\
\text { so we deal with an accelerated motion. But there } \\
\text { is no force on an object moving with zero } \\
\text { acceleration. }\end{array}$ \\
\hline Catherine & Force creates motion. & $\begin{array}{l}\text { Well I know a lot more now. There is no friction } \\
\text { and you push someone and he keeps moving and } \\
\text { then you need another force to stop him or when } \\
\text { there is a continuous force on an object then } \\
\text { there is an acceleration. }\end{array}$ \\
\hline Dan & $\begin{array}{l}\text { Force, or applied force, you know, } \\
\text { an agent that can push or pull an } \\
\text { object. Motion is when an object is } \\
\text { moving. There must be an agent to } \\
\text { create motion. }\end{array}$ & $\begin{array}{l}\text { We need force to create motion. The } \\
\text { relationships between these two concepts are well } \\
\text { explained in Newton's laws. For example, an } \\
\text { object in motion stays in motion unless there is a } \\
\text { kind of force put on it. }\end{array}$ \\
\hline Elena & $\begin{array}{l}\text { Force makes objects move. When } \\
\text { the applied force is gone the object } \\
\text { stops finally. If I push a car it starts } \\
\text { moving but it stops finally. But if } \\
\text { the driver starts the car then it } \\
\text { keeps going since the engine } \\
\text { provides the applied force." }\end{array}$ & $\begin{array}{l}\text { We need a force to cause motion but we don't } \\
\text { need a force to keep moving. If I push my friend } \\
\text { in hockey, he keeps moving since the friction is } \\
\text { very small. We also have different kinds of } \\
\text { motion. Uniform motion, accelerated motion. To } \\
\text { have acceleration, we need to have a net force, } \\
\text { but in a uniform motion the net force is zero. }\end{array}$ \\
\hline Frank & $\begin{array}{l}\text { Force is pushing and motion is } \\
\text { moving. You push something and } \\
\text { moves. }\end{array}$ & $\begin{array}{l}\text { Force is in newtons and is the result of pressure. } \\
\text { Like applied force. I push you and the result of } \\
\text { this pressure is force. Motion is the result of } \\
\text { force. I push you and you move. If you don't } \\
\text { move, then there is another force that is against } \\
\text { your motion. Like friction. That is why we } \\
\text { usually talk about a net force in physics." }\end{array}$ \\
\hline Gabriella & $\begin{array}{l}\text { An object in motion has speed. If a } \\
\text { kind of force is exerted on an } \\
\text { object, the speed will change. }\end{array}$ & $\begin{array}{l}\text { I know more about force and motion now. A } \\
\text { force can change the direction of motion and also } \\
\text { the speed of an object. This is what Newton's } \\
\text { second law is about. The relationship between } \\
\text { force and acceleration and there is an } \\
\text { acceleration when the velocity changes. }\end{array}$ \\
\hline
\end{tabular}


(students' explanation of the relationship between force and motion at the beginning and end of the semester) suggests that all interviewees experienced an expansion of their horizon during the semester.

All interviewees except for Frank argued that they used their pre-understanding, going back and forth between their horizon and that of the textbook, making comparisons with and reasoning about the materials presented.

\subsection{Students' Reflective Writing Products}

In this section, we review the Reflective Writing products of each interviewee. In the next section, we will assess the writing products of a randomly selected cohort of non-interviewed students enrolled in Phys1201 course in order to triangulate with and improve our understanding of the results. The analysis of the interviewees' Reflective Writing products helped us to confirm that they were actually doing what they said they were doing in the interviews.

\section{Ahmed's Reflective Writing Products}

In the third Reflective Writing assignment Ahmed explained his understanding of the limitations and restriction of using projectile motion formulae in real life situations: "for the purpose of giving real life examples, most of the time in this course we will pretend that air resistance is negligible in order to get an idea of what the object should do." Even though he explained the main concepts in his own words, he didn't use a Reflective Writing style to discuss the factors such as launching angle and initial velocity affecting a projectile motion. In the post-interview, Ahmed mentioned explaining part of his learning strategy: "In my opinion I understand something when I can teach it or explain it. Reflective writing is like explaining materials" and this is consistent with his writing products. However, when a topic such as "projectile motion" contains many writing assignments to assess equations and formulas there is not enough effort in understanding behind each equation.

In his fourth Reflective Writing assignment about Newton's first law and forces, he made a good connection between the new concepts and the ones taught in the previous chapters. Beside the explanation of an example provided in the textbook, he talked about his experiences of gravitational force and driving to clarify Newton's first law. He used his own real world experiences to explain the main concepts such as friction: " $A$ good example of humans overcoming friction comes from waterslides. To go down a regular slide there is too much friction to allow your pants to slide down the inclined plane at a very fast speed. However, when you run water down the inclined plane it reduces the amount of friction between you and the slide allowing you to travel down the slide much faster causing a much more exciting ride."

In his next assignment about Newton's second law, he provided a summary of the concepts presented in the textbook as well as his own understanding of them. When a topic was easier to understand, Ahmed relied more on his own understanding and didn't make comparisons between his understanding and the ma- 
terials presented in the textbook. In contrast when the topic was sophisticated, he provided a summary of the concepts as well as his own understanding of them and tried to make a comparison to make sure that his understanding agrees with the textbook. He explained that:

"Newton's second law means that if a body is accelerating, then there is a net force on it and we call this kind of motion an accelerated motion. This is consistent with the fact that net force is zero in a uniform motion. If the net force is aimed in a positive direction, then it will create a positive change in velocity and therefore acceleration is positive. In the second assignment, we talked about the sign of acceleration and when I compare this topic to the second assignment the concept of force and acceleration make perfect sense."

\section{Bill's Reflective Writing Products}

He started the fifth Reflective Writing assignment about Newton's second law and forces by providing an example: "It's a cold winter day, and my car won't turn on to get me home. My best friend suggests that he'll push the car to get it moving. The push that my best friend is applying is a force. The push or pull of an object to another object was one of the definitions mentioned for force" and he manipulated the same example to explain other concepts such as Newton's second law: "If my best friend and I were to push on the car together, there would be twice the amount of force applied on the car. Once the car gets moving, the car is speeding up. Hence, it is accelerating. If applying a force creates acceleration on the object, there is a relation between the two." The expansion of his horizon is obvious in this writing product. For example, he knew that by applying more force on an object, it will accelerate more, but he didn't know about the relationship between mass and acceleration: "I recall the second law as when a force is applied to an object, the object will accelerate. Force and acceleration are directly proportional to each other. If one increases, the other one will too. I didn't remember that mass could have a relationship too with force." What he recalled of the concept of force was just a push or pull on the object, but by reading the textbook he found that force is a vector quantity and could use what he learned in the first chapter about vectors in this topic. As he mentioned in the post-interview, he used his own reasoning in this assignment to make sense of the materials presented: "What is equilibrium I asked myself when I first saw the title of this section of the textbook. Even after reading this passage once then having to write about it, all I got out of it was acceleration equals zero, which didn't connect in my mind with the world equilibrium."

\section{Catherine's Reflective Writing Products}

Her fourth Reflective Writing product provides a summary of Newton's first and second laws. The examples provided to clarify Newton's second law show that Catherine understood this topic well. However, the definition of natural state and what Newton's first law is about were summarized from the textbook. There is no example provided to explain what Newton's first law means, which suggests that it was hard for Catherine to find an example of Newton's first law 
in real life. Her explanation of Newton's first law contains an ideal situation in which there is no force acting on the object: "If there is no force acting on a particular object, the object will stay at rest and if it is moving, it will keep going at the same speed along a straight line. However, there will always be some external forces involved when looking at an object's motion." Catherine provided a summary of the concepts covered previously, but didn't relate them to the new concepts in her writing assignment. The example provided to clarify Newton's second law is the explanation of a numerical example provided in the textbook. As she explained in her pre-interview, the examples provided in the textbook helped her think about the situations related to the concepts and in this assignment the numerical example provided in the textbook inspired her to explain it in her own words: "There are usually some examples in the textbook that help me come up with a good example." The assignment ends with the student's methodology to solve the problems related to Newton's second law.

Catherine explained her own experience of pushing a chair to clarify Newton's second law in the fifth writing assignment. Clear explanations of the main concepts and the relationship among them suggest that Catherine spent a great deal of time thinking about the concepts and explaining them in her own words in this assignment. She also provided a real-world example to explain Newton's first law and its relationship to the second law. This assignment confirms what she said in the post-interview: "To be honest I didn't take the course seriously and I just wanted to pass it but after the first midterm I realized I would have to work hard to pass it."

\section{Dan's Reflective Writing Products}

A summary of the main concepts as well as student's own understanding are presented in Reflective Writing 4 and 5 about Newton's first and second laws. Most examples are numerical and the strategies of solving problems are emphasized: "On the moon an astronaut jumps 2 feet straight up, despite the weight of his space suit which weighs 370 on earth. On the moon, he and his suit together weighed only 90 pounds with $g=1.6 \mathrm{~m} / \mathrm{s}^{2}$." The explanations of equations are clearer and there are examples provided to clarify the formulas: "The Newton's second law equation shows that the acceleration vector points in the same direction as the net force vector. When several forces act on an object, we have to watch and make sure not to think that the strongest force will overcome all the other forces because it will not. It is the net force or the sum of all forces. Forces are vectors and we need to add them using vector rules. So, the force in the Newton's law equation is the net external force and acceleration has the direction of this net force." Dan also explained in Reflective Writing 5 the unit of force based on the Newton's second law formula.

Elena

Writing assignments 5 and 6 are similar to assignment 4 . There are conceptual examples in addition to numerical examples to clarify the meaning of the con- 
cepts. Elena tried to make connections between Newton's second law and the concept of acceleration.

\section{Frank}

Frank explained in both pre- and post-interview that the examples provided in the class and textbook helped him get a better understanding of the concepts. He provided a good explanation of Newton's laws in his writing assignments.

\section{Gabriella}

Gabriella explained both Newton's second law and Newton's third law in one assignment and provided examples to explain the relationship between them:

"I use Newton's third law and Newton's second law when I go swimming with my friends and we try to race each other. While starting I use my feet to push off the wall. The more force I apply on the wall, the faster I am moving in the water. This is because the wall exerts the same force on me as I apply on the wall, but in the opposite direction. When the force from wall on me is bigger, based on Newton's second I have a bigger acceleration which means that change in velocity in a time interval is bigger and I have a great chance to win the race."

Gabriella also related Newton's first law and Newton's second law and also integrated diagrams and photos in this assignment:

"An object in motion at constant velocity will continue to remain in motion in a straight line unless an outside/unbalanced force acts on it. It is this outsidel unbalanced force known as net force that when acting on an object can change the velocity (magnitude and/or direction) and cause the object to accelerate that creates Newton's Second Law. It is simply a continuation of Newton's First Law. After reading the textbook section on Newton's second law, the figures and examples seemed confusing to me. I had no idea why forces acting on an object were projected on $x$ and $y$ axis. But when I understood the relationship between outside/unbalanced force and acceleration they all made sense."

\subsection{Study of Non-Interviewed Students}

To examine the consistency of the above results we examined, the writing products of non-interviewed students who completed Reflective Writing assignments and gave permission to use their writing products in this study. Sample student responses are given in Table 3 for both the beginning and end of the semester. Note that student explanations of acceleration and Newton's second law often refer to one-dimensional cases. In the topic of projectile motion and circular motion students need to think about motion in two dimensions and the effect of forces in a two-dimensional case which violates their intuition that things always go in the direction that one kicks them (White, 1984).

\section{Conclusion}

The strength of this combined approach is its emphasis on writing, metacognition, and the development of conceptual knowledge. Students/peers are challenged to compare their ideas with accepted scientific views since as previously 
Table 3. Comparison of student explanations of the force and motion concepts at the beginning and end of the semester.

\begin{tabular}{|c|c|c|}
\hline Student & Beginning of the semester & End of the semester \\
\hline 1 & $\begin{array}{l}\text { The concept of acceleration is the } \\
\text { amount of how fast an object is moving } \\
\text { by time. }\end{array}$ & $\begin{array}{l}\text { An unbalanced force can change the direction } \\
\text { or magnitude of velocity. We know that } \\
\text { acceleration is related to change in velocity } \\
\text { and so there is a net force acting on an object } \\
\text { in an accelerated motion. }\end{array}$ \\
\hline
\end{tabular}

Displacement is the area travelled by an

object with respect to a starting point and

2 the distance is [has] the whole area

The work done by a force is related to the travelled from the starting point to the final point. displacement. Displacement is a vector that shows the position of an object with respect to its initial position.

A projectile motion is a uniform motion since the initial velocity is the same as

Dynamic equilibrium is the same concept as

3 final velocity and velocity is zero in the uniform motion in which velocity is constant middle and the parabola is uniform. The and acceleration is zero. acceleration is also uniform and is -9.81

Velocity is a vector quantity, meaning magnitude and direction which is the

In a dynamic equilibrium, velocity is constant

4 distance an object has travelled relative to which means that change in object's position its starting point at two specific points in over a given amount of time is constant. time.

Acceleration means speed is increasing and deceleration means speed is

An object accelerates when its velocity changes. Newton's second law shows that

5 decreasing and accelerated motion means when an unbalanced force acts upon on an uniform increase in speed and has a direction since it is a vector. object the velocity changes and object accelerates.

Acceleration is the slope of velocity and velocity has a slope when object moves uniformly and this means that acceleration is constant and slope of acceleration is zero. A positive slope of velocity means that acceleration is positive and doesn't mean that direction of motion is positive

Acceleration and velocity have the same sign when an object is speeding up. An object speeds up when I drop it and so acceleration must be negative since velocity is downward. When it comes to Newton's second law, net force is downward and has the same direction as acceleration.

Acceleration is a vector quantity meaning it has direction and magnitude. Acceleration is Acceleration is most closely related to position versus time, just has a the rate of change of an object's velocity in relation to the time. Newton's second law states that an object's acceleration is dependent on two variables, the net force acting on it, and the object's mass.

Acceleration is the curve of velocity time graph. In a velocity time graph the line would curve representing that the object is speeding up. In a uniform motion velocity time graph is a straight line. An example of acceleration would be a car speeding up from rest after the traffic light turns green. In this example Newton's second law of motion states that when a net force acts on an object, it will change the object's velocity and cause an object to accelerate. The shape of the velocity time graph reveals useful information about the acceleration. A horizontal line shows that acceleration is zero. A positive slope shows a acceleration is positive. Acceleration can positive acceleration and a negative slope also be negative which shows that the shows a negative acceleration. 
Uniform motion is a constant velocity time period, which means you were traveling at a steady unchanging speed at any time.

Displacement is the change in position travelled.
Uniform motion is when an object is travelling at a constant velocity. When velocity is constant then acceleration is zero.

If a body has no acceleration, then the forces acting on it must be in equilibrium and so there must be a zero net force.

By reading the textbook I learned that gravitational potential energy depends on the height of an object not the path travelled. I conclude that gravitational potential energy depends on the displacement in y direction. Now I understand the distinction between distance and displacement. Displacement is the difference in where you start vs where you end, while distance is the total path covered.

Uniform motion is a pretty easy one to explain, in that it is the movement an objects makes in constant time without changing the position in each period of constant time and how fast it is going.

Uniform motion is the rate at which an object moves at equal distances. It doesn't mean that direction of motion is positive even if it is positive. A pendulum would be going in uniform motion because it is travelling the same distance every time.
Newton's first law states that every object stays at rest or in uniform motion (motion in a straight line with constant speed and direction) unless a net external force acts on it.

The key point is that if there is no net external force acting on an object and thus the object maintains a constant velocity. If that velocity is zero, then the object stays at rest. If the velocity is not zero, then the object maintains that velocity and moves in a straight line, which means the direction of motion is also constant.

noted each time the students reach a checkpoint they review the answers with the lab instructor. If the answer to a question is wrong or students are not proceeding in the right direction, the lab instructor leads the students to find the correct answer by themselves, exploring and discussing alternative ideas.

We have demonstrated that the combined use of Reflective Writing and Labatorials in an introductory physics classroom leads to conceptual change; i.e., a conversion of pre-existing concepts of force and motion to the Newtonian viewpoint. Students significantly increase their knowledge of Newton's theory of force when exposed to these interventions. This result is apparent because at the end of the semester interviewees discussed the relationship between force and motion in detail and used other physics concepts such as acceleration and Newton's laws to support their explanations. The consistency of the interviewees with the class in general was given by examination of the writing products of 12 random non-interviewed students who completed Reflective Writing assignments and gave permission to use their writing products in this study.

Further research should be done to get an in depth understanding of how conceptual change occurs with these interventions and to find ways to strengthen this change. 


\section{References}

Chi, M. T. H. (2013). Two Kinds and Four Sub-Types of Misconceived Knowledge, Ways to Change It, and the Learning Outcomes. In S. Vosniadou (Ed.), International Handbook of Conceptual Change (2nd ed., pp. 49-70). New York: Routledge. https://doi.org/10.4324/9780203154472.ch3

Confrey, J. (1990). Chapter 1: A Review of the Research on Student Conceptions in Mathematics, Science, and Programming. Review of Research in Education, 16, 3-56. https://doi.org/10.3102/0091732X016001003

Driver, R. \& Easley. J. (1978). Pupils and Paradigms: A Review of Literature Related to Concept Development in Adolescent Science Students. Studies in Science Education, 5, 61-84. https://doi.org/10.1080/03057267808559857

Driver, R., Rushworth, P., Squires, A., \& Wood-Robinson, V. (1994). Making Sense of Secondary Science: Support Materials for Teachers. London: Routledge.

Duit, R. (2009). Bibliography STCSE: Students' and Teachers' Conceptions and Science Education. Kiel, Germany: University of Kiel.

Feyerabend, P. K. (1962). Explanation, Reduction, and Empiricism. In H. Feigl, \& G. Maxwell (Eds.), Scientific Explanation, Space, and Time, Minnesota Studies in the Philosophy of Science (Vol. 3, pp. 28-97). Minneapolis, MN: University of Minnesota Press.

Gadamer, H.-G. (1975/1960) Truth and Method. In Maxwell (Eds.), Minnesota Studies in the Philosophy of Science (Vol. III). Crossroads, New York: University of Minneapolis Press.

Kalman, C. S. (2011). Enhancing Students' Conceptual Understanding by Engaging Science Text with Reflective Writing as a Hermeneutical Circle. Science \& Education, 20, 159-172. https://doi.org/10.1007/s11191-010-9298-Z

Kalman, C. S., \& Rohar, S. (2010). Toolbox of Activities to Support Students in a Physics Gateway Course. Physical Review Special Topics-Physics Education Research, 6, Article ID: 020111. https://doi.org/10.1103/PhysRevSTPER.6.020111

Kalman, C. S., Shore, B. M., Aulls, M. W., Antimirova, T., Magon, J. K., Lee, G., Coelho, R., Coban, G. U., Huang, X., Ibrahim, A., Wang, X., Tan, D. D. M., Fu, G., \& Khanam, W. (2017). Changing Students' Approach to Learning Physics in Postsecondary Gateway Courses. International Research in Higher Education, 2 (3), 17-33.

Kalman, C., Milner-Bolotin, M., Aulls, M. W., Charles, E. S., Coban, G. U., Shore, B., Antimirova, T., Kaur Magon, J., Xiang, H., Ibrahim, A., Wang, X., Lee, G., Coelho, R. L., Tan, D. D. N., \& Fu, G. (2014). Understanding the Nature of Science and Nonscientific Modes of Thinking in Gateway Science Courses. In M. F. Taşar (Ed.), Proceedings of the World Conference on Physics Education (pp. 1291-1299). Ankara, Turkey: Pegem Akademi.

Kuhn, T. (1987/2000). What Are Scientific Revolutions? In J. Conant, \& J. Haugeland (Eds.), The Road Since Structure (pp. 6-27). Chicago: University of Chicago Press (A Collection of Kuhn's Last Philosophical Essays).

Kuhn, T. S. (1970). The Structure of Scientific Revolutions (2nd ed.). Chicago, IL: University of Chicago Press.

Lattery. M. J. (2017). Deep Learning in Introductory Physics: Exploratory Studies of Modeling-Based Reasoning. Charlotte, NC: Information Age Publishing.

McDermott, L. C., \& Redish, E. F. (1999). Resource Letter: PER-1: Physics Education Research. American Journal of Physics, 67, 755-767. https://doi.org/10.1119/1.19122

McDermott, L. C., \& Shaffer, P. S. (1998). Tutorials in Introductory Physics. Upper Sad- 
dle River, NJ: Prentice Hall.

Novak, J. D. (1977). A Theory of Education. Ithaca, NY: Cornell University Press.

Oberheim, E., \& Hoyningen-Huene, P. (2009). The Incommensurability of Scientific Theories. In E. N. Zalta (Ed.), The Stanford Encyclopedia of Philosophy.

Ram, A., Nersessian, N. J., \& Keil, F. C. (1997). Guest Editors' Introduction. The Journal of the Learning Sciences, 6, 1-2. https://doi.org/10.1207/s15327809jls0601_1

Sobhanzadeh, M., Kalman, C. S., \& Thompson, R. I. (2017). Labatorials in Introductory Physics Courses. European Journal of Physics, 38, Article ID: 065702.

https://doi.org/10.1088/1361-6404/aa8757 


\section{Appendices}

\section{Appendix A: Interview Questions}

\section{Pre-interview}

Q1. How do you study for the course PHY1201?

Probe: You told me that you use... to study for this course. What other materials do you use in studying for this course?

Probe: Do you use your own reasoning, past experiences, what the teachers say, what you read in books?

Q2. Before the next question, let me first give you the definition of pre-understanding. You may already have some ideas about physical concepts, such as force, velocity, mass and so on. These ideas may come from your former educational experience, or from your experience of the real world. Let's call all those ideas in your mind before you entered this course your pre-understanding. How do you think this pre-understanding helps you?

Probe: Do you bring your pre-understanding into studying for this course?

Q3. What was your understanding of the relationship between force and motion before entering the course PHYS 1201 (pre-understanding)?

Probe: Did your pre-understanding help you understand the relationship between force and motion? How?

Q4. How do you think the role of this pre-understanding helped you in your study?

Q5. What do you expect out of the course?

Probe: Does reflective writing activity help you meet your expectations of the Phys 1201 course? How (in which way)?

Probe: Do you find labatorials helpful for you when studying for this course? Why?

Probe: Does labatorial activity help you meet your expectations of the Phys 1201 course? How (in which way)?

Probe: Do you find reflective writing activity helpful for you when studying for this course? Why?

Q6. What do you expect out of the labatorials?

Probe: Does the reflective writing activity help you meet your expectations of labatorials? How (in which way)?

Q7. How do you work on each labatorial worksheet in the lab?

Q8. How do you do your reflective writing activity?

Q9. Did you find reflective writing helpful for you when studying for this course? Why?

Probe: How helpful is reflective writing for you in the lab?

Q10. Did you find labatorials helpful for you when studying for this course? Why?

Q11. If the answer to Q2 is yes, how does reflective writing help you use your pre-understanding? 
Probe: How does reflective writing help you to engage in your studying process?

Q12. If the answer to Q2 is yes, how does the labatorial activity help you to use your pre-understanding?

Probe: How does labatorial activity help you to engage in your studying process?

Q13. Do you think that physics knowledge can change? How?

\section{Post-interview, winter 2014}

Q1. How do you study for the course Phys 1201?

Probe: So you told me that you use ... to study for this course. What other materials do you use in studying for this course?

Probe: How do you get physics knowledge? What do you rely on for getting knowledge?

Probe: Do you use your own reasoning, past experiences, what the teachers say, what you read in books?

Q2. Are your ideas about learning physics different now, compared to before you took this course?

Probe: What experiences in this course had helped you shape your ideas about learning physics? How did these things influence you?

Q3. What exactly did you do at the beginning of this course to promote your learning of the content?

And what exactly did you do in the middle of this course to promote your learning of the content?

What exactly did you do at the end of this course to promote your learning of the content?

Q4. Before the next question, let me first give you a definition of pre-understanding. You may already have some ideas about physical concepts, such as force, velocity, mass and so on. These ideas may come from your former educational experience, or from your experience of the life world. Let's call all those ideas in your mind before you entered this course your pre-understanding. What do you feel were the concepts contained in your pre-understanding?

Probe: Would you define your understanding of pre-understanding? What do you consider as your pre-understanding?

Probe: Did you bring your pre-understanding into studying for this course?

Q5. How did you use this pre-understanding in this course?

Probe: What if what you read (or what teacher says) is not consistent with your pre-understanding? What do you do in this case?

Probe: In what way does your pre-understanding help you in studying for this course? (or if it does not help you can you explain why?)

Probe: Have the concepts in your pre-understanding been changed by taking this course?

Q6. What was your understanding of the relationship between force and motion before entering the course PHYS1201? 
Probe: Did your pre-understanding help you understand the relationship between force and motion? How?

Q7. What is your understanding of the relationship between force and motion now?

Probe: What activities help you shape your present ideas about the relationship between force and motion?

Q8. How did you go from your pre-understanding to your present ideas about the relationship between force and motion?

Q9. Based on the procedure you just described, how does reflective writing help you in examining your ideas?

Probe: What about labatorials? Did they help you to engage into the procedure? How?

Q10. In our pre-interview you told me about your expectations of this course. Did the Phys 1201 course meet your expectations?

Probe: How do you feel about the course right now?

Probe: Did reflective writing activity help you meet your expectations of the Phys 1201 course? How?

Q11. You also told me about your expectations of labatorials in our pre-interview. Did Phys 1201 labatorials meet your expectations?

Probe: What did you get out of labatorials?

Probe: Did the reflective writing activity help you meet your expectations of labatorials? Would you explain how?

Q12. How did you do your reflective writing activity?

Probe: Did you change your procedure of doing reflective writing during the semester? Why? What did you change?

Q13. Did you find reflective writing helpful for you when studying for this course?

Q14. Did you find labatorials helpful for you when studying for this course?

Q15. Do you think that physics knowledge can change? How? 


\section{Appendix B}

Table B1. Reflective writing rubric.

\begin{tabular}{|c|c|c|c|c|c|}
\hline & $\begin{array}{l}\text { Points } \\
\text { Features present in the } \\
\text { reflective writing } \\
\text { product }\end{array}$ & $\begin{array}{c}3 \\
\text { Meets criteria fully }\end{array}$ & $\begin{array}{c}2 \\
\text { Meets most of the criteria }\end{array}$ & $\begin{array}{c}1 \\
\begin{array}{c}\text { Minimally meets the } \\
\text { criteria }\end{array}\end{array}$ & $\begin{array}{c}0 \\
\text { Does not meet the criteria }\end{array}$ \\
\hline 1 & $\begin{array}{l}\text { A fluent piece of work } \\
\text { in the student's own } \\
\text { words }\end{array}$ & $\begin{array}{l}\text { Thoughts flow in a mostly } \\
\text { logical manner, self-talk is } \\
\text { present to monitor } \\
\text { thinking }\end{array}$ & $\begin{array}{l}\text { Thoughts flow in an } \\
\text { associative manner, shows } \\
\text { some self-talk }\end{array}$ & $\begin{array}{l}\text { The student is not thinking } \\
\text { about their own thoughts } \\
\text { but is mostly paraphrases } \\
\text { of material presented in the } \\
\text { textbook or your lectures }\end{array}$ & $\begin{array}{l}\text { The piece is a summary; it is } \\
\text { essay writing, directly } \\
\text { copied from a text book }\end{array}$ \\
\hline 2 & $\begin{array}{l}\text { Student explains key } \\
\text { concepts in his or her } \\
\text { own words }\end{array}$ & $\begin{array}{l}\text { Student has constructed } \\
\text { his/her own understanding } \\
\text { of the concepts and has } \\
\text { used his/her own reasoning } \\
\text { to make sense of the } \\
\text { concepts }\end{array}$ & $\begin{array}{l}\text { Students has used his/her } \\
\text { own reasoning to make } \\
\text { sense of the concepts, but } \\
\text { some key concepts are } \\
\text { missing }\end{array}$ & $\begin{array}{l}\text { Concept written in a } \\
\text { manner that is largely a } \\
\text { rewrite of "textbook" } \\
\text { version. Illustrates } \\
\text { selection of a concepts with } \\
\text { little consideration of its } \\
\text { meaning }\end{array}$ & $\begin{array}{l}\text { Rewrite of a textbook } \\
\text { definition }\end{array}$ \\
\hline 3 & $\begin{array}{l}\text { Student relates recently } \\
\text { introduced key } \\
\text { concepts to previously } \\
\text { studied concepts within } \\
\text { the course }\end{array}$ & $\begin{array}{l}\text { Sets out clear } \\
\text { understanding of how the } \\
\text { concept follows from or is } \\
\text { related to concepts } \\
\text { previously studied in the } \\
\text { course. Student is able to } \\
\text { use the same principle to } \\
\text { explain various } \\
\text { phenomena. }\end{array}$ & $\begin{array}{l}\text { Partial understanding of } \\
\text { how the concept follows } \\
\text { from or is related to } \\
\text { concepts previously } \\
\text { studied in the course }\end{array}$ & $\begin{array}{l}\text { Mention of previously } \\
\text { studied concepts without } \\
\text { any explanation of how } \\
\text { they relate to concepts } \\
\text { under study in current } \\
\text { sections }\end{array}$ & $\begin{array}{l}\text { No relationships to } \\
\text { previously studied concepts } \\
\text { are given. }\end{array}$ \\
\hline 4 & $\begin{array}{l}\text { Student relates key } \\
\text { concepts to his/her own } \\
\text { life experiences }\end{array}$ & $\begin{array}{l}\text { Shows clear understanding } \\
\text { of how the concepts occur } \\
\text { in everyday situations }\end{array}$ & $\begin{array}{l}\text { Shows partial } \\
\text { understanding of how the } \\
\text { concepts occur in everyday } \\
\text { situations }\end{array}$ & $\begin{array}{l}\text { Mention of everyday } \\
\text { situations without any } \\
\text { explanation of how they } \\
\text { relate to concepts under } \\
\text { study in current sections }\end{array}$ & $\begin{array}{l}\text { No relationships to his/her } \\
\text { own life experiences are } \\
\text { given }\end{array}$ \\
\hline 5 & $\begin{array}{l}\text { Student identifies that } \\
\text { the ideas/facts/data } \\
\text { (if applicable) presented } \\
\text { in the textbook are in } \\
\text { conflict with the } \\
\text { students' own ideas }\end{array}$ & $\begin{array}{l}\text { Clearly sets out how the } \\
\text { student's own ideas about } \\
\text { concepts differ from the } \\
\text { versions found in the } \\
\text { textbooks }\end{array}$ & $\begin{array}{l}\text { Sees that there is a conflict } \\
\text { between the students' own } \\
\text { ideas and versions found in } t \\
\text { textbooks without clearly } \\
\text { setting out the difference }\end{array}$ & $\begin{array}{l}\text { Notes a difference between } \\
\text { the students' own ideas and } \\
\text { the versions found in the } \\
\text { textbooks without any } \\
\text { explanation }\end{array}$ & $\begin{array}{l}\text { No conflicts identified } \\
\text { Student's reflective writing } \\
\text { product contains some } \\
\text { conflicts that students has } \\
\text { not realized and addressed. }\end{array}$ \\
\hline 6 & $\begin{array}{l}\text { If there is any conflict } \\
\text { identified, student } \\
\text { discusses the conflict } \\
\text { between the } \\
\text { ideas/facts/data }\end{array}$ & $\begin{array}{l}\text { Student sets out a } \\
\text { discussion of the difference } \\
\text { between the students' own } \\
\text { ideas and the versions } \\
\text { found in the textbooks } \\
\text { trying to fully understand } \\
\text { the difference }\end{array}$ & $\begin{array}{l}\text { Student attempts to discuss } \\
\text { the difference between the } \\
\text { students' own ideas and the } \\
\text { versions found in the } \\
\text { textbooks }\end{array}$ & $\begin{array}{l}\text { Student notes the } \\
\text { difference between the } \\
\text { students' own ideas and the } \\
\text { versions found in the } \\
\text { textbooks without any } \\
\text { discussion }\end{array}$ & No discussion \\
\hline 7 & $\begin{array}{l}\text { In addition to } \\
\text { identifying a conflict, } \\
\text { Student formulates } \\
\text { his/her own } \\
\text { question(s). }\end{array}$ & $\begin{array}{l}\text { Student realizes that there } \\
\text { are concepts in the } \\
\text { textbook that s/he does not } \\
\text { understand and elaborates } \\
\text { a clear question. }\end{array}$ & $\begin{array}{l}\text { Student sets out a question } \\
\text { that is not clearly } \\
\text { formulated }\end{array}$ & $\begin{array}{l}\text { The question formulated } \\
\text { does not address the } \\
\text { conflict between the } \\
\text { students' own ideas and the } \\
\text { versions found in the } \\
\text { textbooks. }\end{array}$ & No questions given \\
\hline
\end{tabular}




\section{Continued}

Student attempts to

8 address his/her own meaningful questions
Student attempts to answer Student makes an attempt questions arising (point 7) to answer questions arising in a lengthy clear discussion using his/her own reasoning

cussion without his/her own reasoning.
Student attempts to answer

questions arising (point 7) No attempt to answer a

in a rambling unclear

discussion

\section{question}

